Center for Injury Research and Policy, Center for Gun Policy and Research, Johns Hopkins University, Bloomberg School of Public Health,

Baltimore

D W Webster

J S Vernick

L M Hepburn

Correspondence to: Daniel W Webster, Center for Injury Research and

Policy, Johns Hopkins School of Public Health, 624 N Broadway, Rm 593,

Baltimore, MD 21205-1996, USA

dwebster@jhsph.edu

\title{
Relationship between licensing, registration, and other gun sales laws and the source state of crime guns
}

\author{
D W Webster, J S Vernick, L M Hepburn
}

\begin{abstract}
Objective-To determine the association between licensing and registration of firearm sales and an indicator of gun availability to criminals.

Methods-Tracing data on all crime guns recovered in 25 cities in the United States were used to estimate the relationship between state gun law categories and the proportion of crime guns first sold by in-state gun dealers.

Results-In cities located in states with both mandatory registration and licensing systems (five cities), a mean of $33.7 \%$ of crime guns were first sold by in-state gun dealers, compared with $72.7 \%$ in cities that had either registration or licensing but not both (seven cities), and $84.2 \%$ in cities without registration or licensing (13 cites). Little of the difference between cities with both licensing and registration and cities with neither licensing nor registration was explained by potential confounders. The share of the population near a city that resides in a neighboring state without licensing or registration laws was negatively associated with the outcome.

Conclusion-States with registration and licensing systems appear to do a better job than other states of keeping guns initially sold within the state from being recovered in crimes. Proximity to states without these laws, however, may limit their impact.

(Injury Prevention 2001;7:184-189)
\end{abstract}

Keywords: firearms; evaluation; law; gun control

There is general consensus among scientists that firearm availability is positively associated with homicide risks ${ }^{1}$; assaults with firearms are, on average, much more lethal than assaults with other common weapons. ${ }^{2}$ However, there is much less agreement about the effectiveness of government efforts to control firearm availability. Skeptics of gun control laws argue that criminals can easily evade regulations by acquiring guns through theft, straw purchases (those by legally eligible purchasers on behalf of individuals legally proscribed from purchasing guns), and other difficult-to-regulate private sales. ${ }^{3}$ Cook and colleagues argue that restrictions on legal gun sales can reduce the supply and consequently raise the price of acquiring guns within illicit as well as licit gun markets. Restricted supplies and increased prices may reduce gun availability within these interconnected markets. ${ }^{56}$

In the United States, federal law proscribes gun sales to specific groups deemed to be potentially dangerous, such as persons convicted of serious crimes, and requires criminal background checks of persons buying guns from licensed dealers. But in many states this requirement is fulfilled via "instant check" procedures vulnerable to the use of falsified identification cards and straw purchasers. ${ }^{7}$ Some states in the United States, however, have much more extensive regulatory systems that include registration of firearms, licensing of buyers, and very restrictive eligibility criteria for firearm purchases.

Permit-to-purchase licensing systems require prospective gun purchasers to have direct contact with law enforcement or judicial authorities that scrutinize purchase applications, and some allow these agencies broad discretion to disapprove applications. Some licensing laws require applicants to be fingerprinted and allow officials weeks or even months to conduct extensive background checks. Mandatory registration makes it easier to trace guns used in crime to their last known legal owner, and to investigate possible illegal transfers. In combination, these laws have the potential to significantly restrict gun acquisition by high risk individuals through stricter eligibility criteria, safeguards against falsified applications, and increased legal risks and costs associated with illegal gun transfers to proscribed individuals. Recently, several United States gun control groups have made licensing of buyers and registration of handguns the centerpiece of their advocacy agenda.

Most industrialized countries place broad restrictions on private ownership of firearms. ${ }^{89}$ For example, Canada created a centralized registry for purchased handguns in 1951, and instituted very restrictive permit-to-purchase requirements for handguns in 1969. These restrictions were expanded to long guns in 
1977. ${ }^{8}$ Evaluations of the 1977 law were mixed, but suggested that the law was associated with a reduction in homicides. ${ }^{10-12}$ In a cross sectional study of gun control laws in the United States, Kleck and Patterson also present mixed evidence that permit-topurchase laws were associated with lower rates of homicide. ${ }^{13}$

With few exceptions, ${ }^{14}{ }^{15}$ previous evaluations of state gun sales laws have not examined the state in which the guns used to commit violence were sold. This study addresses this gap by examining whether states with licensing, registration, and other gun sales regulations have proportionately fewer of their crime guns that were originally purchased from within the state. Having a low proportion of crime guns with in-state origins would suggest that guns are relatively difficult for persons at risk for criminal involvement to obtain from in-state gun dealers, acquaintances, or homes that are burglarized. Interstate gun traffickers offer an alternative source of guns to criminals in states with restrictive gun laws, however the costs, risks, and inconvenience are likely to be greater. These added costs might curtail access to guns among high risk individuals ${ }^{5}{ }^{6}$ and consequently reduce rates of lethal violence. ${ }^{216}$

\section{Methods}

STUDY SAMPLE AND DATA

This study uses city level data for 27 cities located in 23 states that have participated in a federally funded program called the Youth Crime Gun Interdiction Initiative (YCGII). Each of these cities agreed to submit information on all crime guns recovered by local law enforcement agencies to the Bureau of Alcohol, Tobacco, and Firearms (ATF) for tracing. (Despite its name, the YCGII was not limited to guns recovered from youth.) In most other jurisdictions, police only attempt to trace a non-random sample of the crime guns they recover, creating the possibility for selection bias. ${ }^{17} \mathrm{~A}$ crime gun was defined by ATF as any firearm that was "illegally possessed, used in a crime, or suspected to have been used in a crime." ${ }^{18}$

Data were available for all 27 cities for all crime guns recovered by police from 1 August 1997 though 31 July $1998 .{ }^{18}$ For 17 of the 27 cities, data were also available for guns recovered from 1 July 1996 through 30 April 1997. ${ }^{19}$ To increase the reliability and sample size of our analyses, we combined data from the two reporting periods for those cities where it was available. Due to limited resources and the difficulty of tracing older guns, ATF did not always attempt to complete traces for guns that were manufactured before 1990. Therefore, in order to study a sample of crime guns that were comprehensively traced, we limited our analyses to recovered crime guns that were sold during or after 1 January 1990. With one exception, discussed below, all of the state licensing and registration laws of interest went into effect well before 1990 .
Proportion of crime guns from in-state gun dealers Our primary outcome measure is the proportion of traceable crime guns that were originally purchased from an in-state gun dealer. In our data, this outcome measure was positively correlated with another indicator of gun availability to high risk individuals-the proportion of homicides of males ages 15 and above that were committed with guns (Pearson's $r=0.40, \mathrm{p}=0.048)$.

\section{State gun sales laws}

Our primary explanatory variable of interest is the set of state level firearm sales laws. Information about these laws was obtained from ATF and United States Department of Justice publications, ${ }^{20}{ }^{21}$ and through legal research. Two key laws of interest were permitto-purchase licensing of firearm buyers and registration of firearms. Based on these laws, we grouped all states into three categories. In category A, we grouped states with both permit-to-purchase licensing and registration. Category B consisted of states with either licensing or registration (but not both). Category C groups those states with neither permit-to-purchase licensing nor registration.

Though our categorization was based on licensing and registration laws, states with both of these laws often have many additional firearm sales restrictions that could enhance the effectiveness of their gun regulatory system (see table 1). For example, states with permitto-purchase laws often require relatively long maximum waiting periods and prohibit gun sales to persons convicted of certain misdemeanor crimes. In addition, states with both licensing and registration typically allowed criminal justice agencies to use discretion in issuing permits.

There was only one state with a change in its gun sales laws from 1 January 1990 though 31 July 1998 that would alter its category. Connecticut enacted its permit-to-purchase licensing and registration system beginning 1 October 1994; but permits for handgun sales were not mandatory until 1 October 1995. Before Connecticut's new law, Bridgeport (one of the YCGII cities) would have been placed in category C; after the law, it would be grouped in category A. Therefore, we excluded Bridgeport from our primary analyses. Instead, we conducted a separate analysis comparing the source state of Bridgeport's crime guns first purchased before and after its regulatory system became available in October 1994, and contrasted this pre-law versus post-law difference with other cities in category C. We chose the 1994 date because it was the earliest date after which handgun buyers were obtaining permits.

We also excluded Washington, DC from our primary analysis. In 1976, the District of Columbia banned most handgun possession and purchase. Therefore, its laws are not truly comparable to the other states we examined.

\section{Potential confounders}

Factors other than gun sales laws, such as proximity to persons living in other states, may 
Table 1 State gun sales laws in effect in 25 Youth Crime Gun Interdiction Initiative cities, overall classification of the set of these laws, and the percentage of the city's crime guns that were first purchased from in-state gun dealers

\begin{tabular}{|c|c|c|c|c|c|c|c|c|c|c|}
\hline $\begin{array}{l}\text { Category of } \\
\text { state's gun } \\
\text { sales laws * }\end{array}$ & City, state & $\begin{array}{l}\text { \% Of city crime } \\
\text { guns first } \\
\text { purchased within } \\
\text { the state }\end{array}$ & $\begin{array}{l}\text { Permit to } \\
\text { purchase }\end{array}$ & Registrationt & $\begin{array}{l}\text { Private } \\
\text { purchases } \\
\text { regulated } \neq\end{array}$ & $\begin{array}{l}\text { Purchase } \\
\text { restrictions: } \\
\text { certain } \\
\text { misdemeanors }\end{array}$ & $\begin{array}{l}\text { Possession } \\
\text { restrictions: } \\
\text { youth }<21 \\
\text { years old }\end{array}$ & $\begin{array}{l}\text { Fingerprint } \\
\text { required on } \\
\text { purchase } \\
\text { application }\end{array}$ & $\begin{array}{l}\text { Maximum } \\
\text { wait }>7 \text { days }\end{array}$ & $\begin{array}{l}\text { One } \\
\text { gun/month }\end{array}$ \\
\hline A & $\begin{array}{l}\text { Boston, MA } \\
\text { Detroit, MI } \\
\text { Jersey City, NJ } \\
\text { New York, NY } \\
\text { St Louis, MO }\end{array}$ & $\begin{array}{l}31.4 \\
47.5 \\
13.0 \\
14.0 \\
62.9\end{array}$ & $\begin{array}{l}x d \\
x d \\
x d \\
x d \\
x\end{array}$ & $\begin{array}{l}\mathrm{X} \\
\mathrm{X} \\
\mathrm{X} \\
\mathrm{X} \\
\mathrm{X}\end{array}$ & $\begin{array}{l}\mathrm{X} \\
\mathrm{X} \\
\mathrm{X} \\
\mathrm{X}\end{array}$ & $\begin{array}{l}\mathrm{X} \\
\mathrm{X} \\
\mathrm{X}\end{array}$ & $\mathrm{x}$ & $\begin{array}{l}\mathrm{X} \\
\mathrm{X}\end{array}$ & $\begin{array}{l}\mathrm{X} \\
\mathrm{X} \\
\mathrm{X} \\
\mathrm{X}\end{array}$ & \\
\hline B & $\begin{array}{l}\text { Baltimore, MD } \\
\text { Chicago, IL } \\
\text { Inglewood, CA } \\
\text { Los Angeles, CA } \\
\text { Minneapolis, MN } \\
\text { Philadelphia, PA } \\
\text { Salinas, CA }\end{array}$ & $\begin{array}{l}73.0 \\
64.7 \\
69.9 \\
78.0 \\
74.4 \\
66.7 \\
82.3\end{array}$ & $\mathrm{x}$ & $\begin{array}{l}\mathrm{X} \\
\mathrm{X} \\
\mathrm{X}\end{array}$ & $\begin{array}{l}\mathrm{X} \\
\mathrm{X} \\
\mathrm{X} \\
\mathrm{X} \\
\mathrm{X} \\
\mathrm{X} \\
\mathrm{X}\end{array}$ & $\begin{array}{l}\mathrm{X} \\
\mathrm{X} \\
\mathrm{X} \\
\mathrm{X} \\
\mathrm{X}\end{array}$ & $\mathrm{X}$ & & $\begin{array}{l}\mathrm{X} \\
\mathrm{X} \\
\mathrm{X} \\
\\
\mathrm{X}\end{array}$ & $\mathrm{X}$ \\
\hline C & $\begin{array}{l}\text { Atlanta, GA } \\
\text { Birmingham, AL } \\
\text { Cincinnati, OH } \\
\text { Cleveland, OH } \\
\text { Gary, IN } \\
\text { Houston, TX } \\
\text { Memphis, TN } \\
\text { Miami, FL } \\
\text { Richmond, VA } \\
\text { Milwaukee, WI } \\
\text { San Antonio, TX } \\
\text { Seattle, WA } \\
\text { Tucson, AZ }\end{array}$ & $\begin{array}{l}86.0 \\
88.3 \\
67.4 \\
85.6 \\
89.3 \\
88.3 \\
70.8 \\
90.1 \\
90.6 \\
80.9 \\
90.0 \\
78.1 \\
89.0\end{array}$ & & & $\begin{array}{l}\mathrm{X} \\
\mathrm{X}\end{array}$ & $\begin{array}{l}\mathrm{X} \\
\mathrm{x}\end{array}$ & $\mathrm{x}$ & $\mathrm{X}$ & $\mathrm{X}$ & $\mathrm{x}$ \\
\hline
\end{tabular}

${ }^{\star}$ Category $\mathrm{A}=$ permit to purchase licensing and registration systems; category $\mathrm{B}=$ permit to purchase licensing or registration but not both; category $\mathrm{C}=$ neither permit to purchase licensing or registration.

tIncludes those states where police retain records of handgun purchases.

$\ddagger$ Permit or background check required for sales through non-licensed dealers.

§Permit issued with law enforcement agency discretion.

also affect the source state of a city's crime guns. The following hypothesized determinants of the proportion of a city's crime guns originating from in-state gun dealers, in addition to gun sales laws, were considered in the analyses: (1) nearest driving distance from the city of interest to another state in category C, (2) the ratio of out-of-state to in-state population within a 50 or 100 mile radius of the city, (3) the proportion of the population within a 50 or 100 mile radius of the city that reside in a state in category C, (4) the proportion of the state's population that had moved from another state within the previous year, ${ }^{22}$ and (5) the proportion of a city's crime guns that were recovered in cases involving drug crimes (illicit drug selling networks often extend across state borders).

Differences in gun ownership between states, attributable to cultural and demographic differences, may be an important determinant of whether restrictive gun sales laws are passed in a state. Lower levels of gun ownership within a state that are independent of the effects of those restrictive laws that are not controlled for in our analysis could bias our estimates of the laws' effects. Controlling for pre-law gun ownership levels is somewhat problematic, however, because direct measures of state level gun ownership are not available and the implementation dates of the laws differ across states. Therefore, we used the per cent of a state's suicides during 1996-97 that were committed with firearms as a proxy measure of gun ownership based on the rationale that this fraction will be strongly influenced by gun availability. ${ }^{23}$ This measure, however, may underestimate the level of pre-law gun ownership not attributable to restrictive gun laws in states that subsequently passed such restrictions because the laws may have depressed gun ownership levels in the effected states. If this is the case, this control variable may overcorrect the estimate of the laws' effects. We, therefore, included this covariate in a sensitivity analysis to provide a lower bound point estimate of the laws' effects.

Population data were obtained from the United States census, ${ }^{24}$ and the population residing within a 50 and 100 mile radius of the center of each city was determined using the Census' Master Area Block Level Equivalency program. ${ }^{25}$ Driving distances from central city locations to the borders of other states were determined using Map Expert 2.0 computer mapping software. ${ }^{26}$

\section{DATA ANALYSIS}

Analysis of variance of the mean proportion of crime guns originating in-state was used for comparisons across the three categories of gun sales laws. Dunnet's C statistic was used to compare between group means with unequal variances. ${ }^{27}$ Ordinary least squares linear regression analysis was used to estimate the independent association between the hypothesized explanatory variables and the outcome. Theoretically relevant covariates were dropped from the model if their effects were not statistically significant and if their exclusion did not appear to influence the other estimates. Cook's distance $^{28}$ and the standardized difference in the beta values were examined to assess whether particular observations exerted undue influence on the regression coefficients.

\section{Results}

For the 25 cities in our analysis, 108000 crime guns were recovered by the police during the 


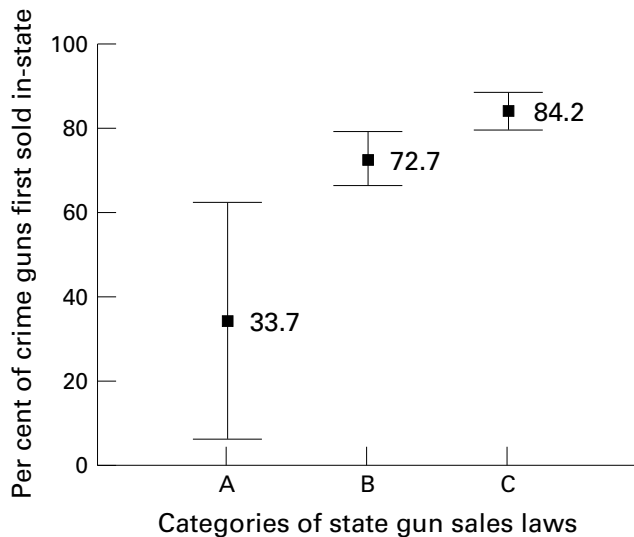

Figure 1 Mean and 95\% confidence interval for the percentage of crime guns first sold by in-state gun dealers by gun law category. Category A: licensing and permit to purchase and at least two other gun sales laws; category B: licensing or permit to purchase but not both; category $C$. neither licensing or permit to purchase.

study period. Because we limit our analysis to crime guns first purchased since 1990, to calculate the proportion of guns in our dataset successfully traced to a source state, it is first necessary to eliminate from the denominator those guns bought before 1990. Using information on the sales dates and ATF's reasons for not completing a trace, we estimated that 60202 guns were first purchased before 1990 . Of the remaining 47798 guns, 35000 (73.2\%) were successfully traced by ATF to a source state.

Table 1 depicts the categorization of the 25 YCGII cities based upon their gun sales laws. In general, the categories are ordered by the comprehensiveness of the laws. The mean percentage of crime guns with in-state origins for category A cities (33.7\%) was significantly less than that for cities in category B $(72.7 \%)$ and category C $(84.2 \%)$ (both differences significant at $\mathrm{p}<0.001$; see fig 1$)$. Apparent in fig 1 and confirmed by a formal test (Levene statistic $=8.58, \mathrm{df} 1=2, \mathrm{df} 2=22, \mathrm{p}=0.002)$ is that the variance in the outcome measure among the five cities in category $\mathrm{A}$ is larger than in categories $\mathrm{B}$ and $\mathrm{C}$.

The regression analyses indicated that the large bivariate differences between cities in category A and those in categories B and C remained after controlling for potential confounders (table 2). The estimates from model 1 indicate that the percentage of crime guns with in-state origins was 48.5 percentage points lower in category A cities compared with category $C$ cities $(p<0.001)$. The percentage of crime guns with in-state origins in category $\mathrm{B}$
Key points

- Only a few states in the United States require firearm owners to be licensed and their guns to be registered.

- The proportion of a city's crime guns that come from in-state, verus out-of-state, is an important measure of how hard it is for criminals to get guns in those states.

- Cities in states with both licensing and registration have a much smaller proportion of their crimes guns coming from in-state.

- Licensing and registration laws can make it harder for criminals and juveniles to get guns.

cities was 12.8 percentage points lower than in category $C$ cities $(p=0.039)$. The percentage of the population within a 100 mile radius of a city that resided beyond the state border in a category $\mathrm{C}$ state was negatively associated with the percentage of crime guns with in-state origins $(\beta=-19.9, \mathrm{SE}(\beta)=7.5, \mathrm{p}=0.016)$.

Model 2 in table 2 presents our findings with the surrogate measure of gun ownership within the state added to the model. This indicator of gun ownership was positively associated with the percentage of crime guns that had been sold by in-state gun dealers $(\beta=0.682, \operatorname{SE}(\beta)$ $=0.180, \mathrm{p}=0.001)$. The magnitude of the estimate for the difference between category A and category $C$ cities was reduced $(\beta=-37.1$, $\operatorname{SE}(\beta)=5.88, \mathrm{p}<0.001)$ but remained large and highly significant. However, the estimate for the difference between category $\mathrm{B}$ versus category $C$ cities was reduced substantially and is no longer statistically significant $(\beta=-4.25$, $\operatorname{SE}(\beta)=4.95, \mathrm{p}=0.402)$.

Population migration into the state and the proportion of recovered guns associated with drug offenses were not significantly associated with the proportion of a city's crime guns first sold by an in-state gun dealer. Driving distance from the city to the nearest state border and distance to the nearest state with weaker gun sales laws were not included in the models due to colinearity with other covariates. The proportion of total population within a 50 mile radius of the city residing outside the state border was not included in the models because its inclusion lead to an extremely large Cook's distance statistic for one city. This covariate did not have a statistically significant effect on the outcome measure, and its exclusion from the models did not substantially effect the gun law estimates.

Table 2 Results from ordinary least squares regression on the percentage of a city's crime guns that were originally purchased from in-state gun dealers

\begin{tabular}{|c|c|c|c|c|c|c|}
\hline \multirow[b]{2}{*}{ Explanatory variables } & \multicolumn{3}{|l|}{ Model 1} & \multicolumn{3}{|l|}{ Model 2} \\
\hline & $\beta(S E)$ & Standardized $\beta$ & Significance & $\beta(S E)$ & Standardized $\beta$ & Significance \\
\hline Category $\mathrm{A} v \mathrm{C}$ state gun sales laws & $-48.5(6.6)$ & -0.886 & $<0.001$ & $-37.1(5.9)$ & -0.678 & $<0.001$ \\
\hline Category B $v$ C state gun sales laws & $-12.8(5.8)$ & -0.261 & 0.039 & $-4.3(5.0)$ & -0.087 & 0.402 \\
\hline $\begin{array}{l}\text { Ratio of population within } 100 \text { mile radius living outside state } \\
\text { border in category C state }\end{array}$ & $-19.9(7.5)$ & -0.239 & 0.016 & $-17.4(5.8)$ & -0.208 & 0.008 \\
\hline $\begin{array}{l}\text { border in category C state } \\
\text { Ratio of annual in-migration to total state population }\end{array}$ & $-0.413(2.6)$ & $\begin{array}{l}-0.259 \\
-0.019\end{array}$ & $\begin{array}{l}0.010 \\
0.876\end{array}$ & $\begin{array}{l}-11.4(3.8) \\
-0.965(2.0)\end{array}$ & $\begin{array}{l}-0.208 \\
-0.045\end{array}$ & 0.037 \\
\hline$\%$ Of guns recovered from drug crimes & $0.548(0.32)$ & 0.155 & 0.100 & $0.114(0.27)$ & 0.032 & 0.676 \\
\hline Proxy for state prevalence of gun ownership & & & & $0.682(0.18)$ & 0.377 & 0.001 \\
\hline Model statistics & $R^{2}=0.85$ & Adjusted $R^{2}=0.82$ & & $R^{2}=0.92$ & Adjusted $R^{2}=0.89$ & \\
\hline
\end{tabular}


The percentage of Bridgeport's crime guns that had been sold by in-state dealers decreased from $84.9 \%(124 / 146)$ for guns purchased before Connecticut's licensing and registration laws went into effect to $81.5 \%$ (44/54) for guns purchased afterward. In contrast, among the other category $\mathrm{C}$ cities, the proportion of crime guns with in-state origins increased from $79.8 \%(6289 / 7883)$ to $87.9 \%(6798 / 7732)$ for guns sold during the same two time periods. While these divergent trends are suggestive of moderate effects from Connecticut's mandatory licensing and registration law, the $81.5 \%$ of Bridgeport's crime guns that had been sold by in-state dealers after the law's effective date was significantly higher than was observed in the five other category A cities.

\section{Discussion}

We found great variation among cities in the percentage of their crime guns that originated from in-state gun dealers. This variation was largely explained by the presence or absence of comprehensive state regulations of gun sales that fit our definition of category A-permitto-purchase licensing and mandatory registration of handguns - and to a lesser degree by proximity to people in states with minimal restrictions on gun sales. After adjusting for confounders, the percentage of crime guns recovered in cities in category A that had been purchased from in-state dealers was less than half as high as would have been expected if the weakest state laws (category C) had been in effect.

The wide variation in the proportion of crime guns from in-state dealers within category A suggests that there are important determinants of our outcome other than the presence of licensing and registration systems. Some of the variance within this category appears to be explained by complementary sales restrictions. Category A cities with the lowest proportion of their crime guns originating from in-state dealers-Boston, Jersey City, and New York-were in states that also allowed law enforcement discretion in issuing permits to purchase handguns, had longer waiting periods, and required purchase applicants to be fingerprinted. In contrast, St Louis, Missouri, with the highest proportion of crime guns sold by in-state gun dealers among category A cities, had none of these provisions.

The very strong cross sectional association between permit-to-purchase licensing and registration laws, and lower proportions of crime guns with in-state origins, is tempered somewhat by the modest change observed in Bridgeport after Connecticut adopted a licensing and registration system. This relatively modest change in Bridgeport may be due to the newness of law, the availability of older used guns purchased within the state prior to the new law, or to the lack of some of the other sales restrictions mentioned above that have been in place for years in other states with licensing and registration systems. In addition, our use of the date the licensing and registration system became operational as the intervention point rather than the date, 12 months later, on which these regulations became mandatory may have created a conservative bias in our findings of the law's effect.

Interestingly, after adjusting for gun ownership as well as other potential confounders, there was no significant difference between cities in categories B and C in the proportion of their crime guns that had originated from in-state gun dealers. This finding suggests that state level gun control measures may not have a substantial impact on criminal gun availability unless the measures are very comprehensive, including both licensing, registration and other restrictions.

The potential benefits from comprehensive state gun control measures appear to be diminished by the lack of such controls in other states. Consistent with other research, ${ }^{18} 1929$ proximity to people living in states with weak gun laws increased the proportion of a city's crime guns originating from out-of-state gun dealers.

There are several potential limitations to this study. First, our outcome measure may seem somewhat removed from the most important public health outcomes such as homicides. However, there is general consensus among scholars that reduced access to guns among high risk individuals is likely to lead to reduced rates of lethal violence, ${ }^{1}$ and the proportion of crime guns that originate from in-state gun dealers should be directly related to how easy it is for high risk individuals to obtain guns. Indeed, we found that the proportion of a city's crime guns that had been sold by an in-state gun dealer was positively associated with another indicator of gun availability to high risk individuals, the proportion of homicides of males ages 15 and above that were committed with firearms.

Criminals and delinquent youth tend to obtain guns in private transactions with acquaintances and to a lesser degree from thefts. ${ }^{29}{ }^{30}$ Although these transactions are difficult to regulate directly, laws that restrict legal gun ownership and gun transfers such as licensing and registration could constrain the supply of guns from these typical sources of crime guns. ${ }^{5}$ With fewer guns from local sources, criminals and juveniles must identify out-of-state sources. But interstate traffickers face barriers and risks that may limit their ability to make up for significant in-state supply restrictions. Perhaps as a result of these supply constraints, street prices of guns in places with very restrictive gun control laws tend to be significantly higher than in places with more lax laws. ${ }^{5}$

Omission or inadequate measurement of confounders is always a potential limitation in evaluations of gun policies. By focusing on the effects of state gun sales law on the proportion of crime guns originating from in-state gun dealers, however, the findings from this study may be less vulnerable to certain threats to validity that can bias gun control evaluations that focus on the laws' effects on violent crime. 
Violent crime is influenced by a large number of factors, many of which are difficult to measure adequately. In contrast, there are likely to be many fewer unmeasured factors that affect the proportion of crime guns from in-state gun dealers-our final models explained $82 \%$ and $89 \%$ of the variance in this outcome.

The relatively small, non-random sample of cities, selected by ATF for their willingness to submit information on all crime guns recovered by police, limits the generalizabililty of the findings. However, the cities in this study are diverse with respect to region and population size, and appear to be representative of their states based on the very high correlation between the cities' and states' measures of our outcome variable $(r=0.97, \mathrm{p}<0.001)$.

Kleck has suggested that police in states with firearm registries may be less inclined to request an ATF trace of a crime gun that is registered within the state because much of the information from the ATF trace may be obtainable from the state registry. ${ }^{17}$ If pervasive within YCGII cities, such practices could bias our findings. However, the police departments that submitted information for this study agreed to submit information to ATF on all recovered crime guns. ATF devoted considerable resources to assist local agencies making trace requests and to oversee the collection of data. ATF officials working on the YCGII indicate that the protocols for initiating ATF trace requests used by the participating police departments were generally independent from other police investigations, whether or not a state had a registration system. Furthermore, the proportion of crime guns sold by in-state dealers when the state had a registration system but no permit-to-purchase licensing system (five of the seven cities in category B) was quite high $(67 \%-82 \%)$ indicating that the agencies were clearly submitting data to ATF for guns that should also be in the state registry.

Our analyses were limited to guns sold less than years years before recovery by the police because ATF did not trace all crime guns manufactured before 1990. Associations between state gun laws and in-state origins of crime guns may differ for older versus newer guns. Any differences between older and newer guns, however, would have to be quite substantial to negate the very large magnitude of effect for category A state laws.

Finally, the way we choose to categorize state gun sales laws limits our ability to estimate of the independent effects of each of type of regulation of interest. Due to the high correlation between the presence of many of the laws we considered, preliminary analyses revealed substantial multicolinearity when we attempted to generated separate estimates for each law of interest.

\section{Implications for prevention}

Understanding the benefits of restrictive firearm sales laws can help policymakers to make informed legislative choices. Our findings suggest that comprehensive gun sales regulations that include permit-to-purchase licensing and registration can affect the availability of guns to criminals. Conversely, the absence of these regulations may increase the availability of guns to criminals in nearby states.

This study was supported by grant R49/CCR3028 from the Centers for Disease Control and Prevention to the Johns Hopkins Center for Injury Research and Policy.

1 Reiss AJ Jr, Roth JA, eds. Understanding and preventing violence: panel on the understanding and control of violent behavior. National Research Council. Washington, DC: National Academy Press, 1993.

2 Cook PJ. The technology of personal violence. In: Tonry M, ed. Crime and justice: a review of research. Vol 14. Chicago: University of Chicago Press, 1991: 1-72.

3 Jacobs JB, Potter KA. Keeping guns out of the "wrong" hands: the Brady law and the limits of regulation. Fournal of Criminal Law \& Criminology 1995;86:93-120.

4 Kleck G. Targeting guns: firearms and their control. New York: Aldine de Gruyter, 1997.

5 Cook PJ, Molliconi S, Cole TB. Regulating gun markets. Fournal of Criminal Law E Criminology 1995;86:59-92.

6 Cook PJ, Leitzel J. Perversity, futility and jeopardy: an economic analysis of the attack on gun control. Law and Contemporary Problems 1996;59:91-118.

7 United States General Accounting Office. Firearms purchased from federal firearms licencees using bogus identification. GAO-01-427. Washington, DC: General Accounting Office, March 2001.

8 Cukier W. Firearms regulation: Canada in the international context. Chronic Dis Can 1998;19:25-34.

9 Zimring FE, Hawkins G. Crime is not the problem: lethal violence in America. New York: Oxford University Press, 1997.

10 Mauser GA, Holmes RA. An evaluation of the 1977 Canadian firearms legislation, Evaluation Rev 1992;16:603-17.

11 Department of Justice, Canada. A statistical analysis of the impacts of the 1977 firearms control legislation. Ottawa: Programme Evaluation Section, Research, Statistics and Evaluation Directorate, July 1996.

12 Morrel-Samuels S. Homicide trends in Canada and the United States: 1962-1991: an examination of the effectiveness of gun control. Presented at the Annual Meetings of ness of gun control. Presented at the Annual Meetings of
the American Public Health Association, November 1994.

13 Kleck G, Patterson EB. The impact of gun control and gun ownership levels on violence rates. Fournal of Quantitative Criminology 1993;9:249-88.

14 Weil DS, Knox RC. Effects of limiting handgun purchases on interstate transfer of firearms. $\mathcal{F} A M A$ 1996;275:175961.

15 Vernick JS, Webster DW, Hepburn LM. Maryland's law banning Saturday night specials: effects on handgun sales and crime guns. Inj Prev 1999;5:259-63.

16 Zimring FE. Firearms, violence and public policy. Scientific American 1991(Nov):48-54.

17 Kleck G. BATF gun trace data and the role of organized gun trafficking in supplying guns to criminals. St Louis University Public Law Review 1999;18:23-45.

18 Bureau of Alcohol, Tobacco, and Firearms. The youth crime gun interdiction initiative: crime gun trace analysis reports: the illegal youth firearms markets in 27 communities. Washington, illegal youth firearms markets in 27 communities. Washingt

19 Bureau of Alcohol, Tobacco, and Firearms. The youth crime gun interdiction initiative: crime gun trace analysis reports: the illegal youth firearm markets in 17 communities. Washington, DC: US Department of the Treasury, July 1997

20 Bureau of Alcohol, Tobacco, and Firearms. State laws and published ordinances - firearms. 1st Ed. Washington, DC: US Department of Treasury, 1998.

21 Bureau of Justice Statistics. Survey of state procedures related to firearms sales, 1997. Washington, DC: US Department of Justice, December 1998

22 US Bureau of the Census. Geographic mobility: March 1996 to March 1997. Current Population Reports. Washington DC: Bureau of the Census, US Department of Commerce, 1998.

23 Cook PJ. The effect of gun availability on robbery and robbery murder. In: Haveman R, Zellner BB, eds. Policy studies bery murder. In: Haveman R, Zellner BB, eds. Policy stu
review annual. Beverly Hills, CA: Sage, 1979: 743-81.

24 United States Census 1998 Population Estimates Update. www.census.gov/population/estimates.

25 Bureau of the Census. MABLE/GeoCorr Geographic Correspondence Engine, version 2.01. www.census.gov/plue.

26 DeLorme Mapping. Map Expert version 2.0 for Windows. Yarmouth, ME: DeLorme Mapping, 1993

27 Dunnett CW. Pairwise multiple comparisons in the unequal variance case. 7 Am Stat Assoc 1980;75:796-800.

28 Cook RD. Detection of influential observation in linear regression. Technometrics 1977;19:15-18.

29 Wright JD, Rossi PH. The armed criminal in America: a survey of incarcerated felons. Washington, DC: National .

30 Sheley JF, Wright JD. In the line of fire: youth, guns, and violence in urban America. New York: Aldine de Gruyter, 1995. 